\title{
CARACTERES DA FUNDAÇĀO DE DIREITO PÚBLICO
}

\author{
Antonio Carlos de Campos Pedroso \\ Professor-Assistente do Departamento de Filosofia e Teoria Geral do Direito da \\ Faculdade de Direito da Universidade de São Paulo
}

Resumo: $O$ texto pretende demonstrar a possibilidade jurídica da fundação de Direito Público. Admitida a configuração dessa entidade, visa indicar os caracteres do seu constitutivo real.

Para atingir mencionado objetivo, procura, de início, analisar os elementos da definição de fundação in genere. O estudo dos conceitos jurídicos fundamentais, nos quais se inclui o de fundação, constitui tema de Teoria Geral de Direito.

Consiste a fundação, segundo lição de V. Rossel e H. Mentha, na "afetação de um patrimônio a um objetivo especial e lícito, com uma organização material e administrativa, comandada pelo objetivo a realizar" Distingue-se pois, das corporações, ou agrupamento de pessoas que, com certa disciplina, unificam seus esforços para a obtenção de um fim comum. Estas são as "universitas personarum", por oposição aquelas, que são as "universitas bonorum"

Admite-se, portanto, na tipologia das pessoas jurídicas, as corporações e as fundações.

O estudo procura demonstrar que a distinçāo operada pela Teoria Geral do Direito, entre fundações e corporações, permite uma configuração paralela de ambas as entidades nas esferas jurídicas do Direito Civil e do Direito Administrativo.

Uma coisa é o "constitutivo real" da fundação, matéria de Teoria Geral do Direito; outra é a configuraçāo específica das entidades segundo princípios setoriais e modelos do Direito Privado e do Direito Público.

Admitindo-se como premissa o conceito de fundaçāo supraindicado, podese chegar, por acréscimo de algumas notas, ao de fundação de Direito Público. Esta é uma entidade criada por lei, tendo por escopo um serviço público determinado pelo Estado; é administrada por um serviço público autônomo (autarquia); tem patrimônio próprio destacado do geral e afetado a um fim público; está sob a tutela permanente do Estado. Tais são os caracteres indicativos de sua diferenciação específica.

Resumé: L'article a le but de montrer la possibilité juridique de la fondation de droit public. Tant que admise ce possibilité, on va indiquer les caracteres de cette figure. D'abord on cherche d'analiser les elements de la definition de fondation "in genere" L'étude des notions juridiques fondamentales, parmi lesquelles celle de fondation, rentre dans les themes de la Teorie Générale du Droit.

Selon V. Rossel e H. Mentha la fondation est "l'afféctation d'un patrimoine a um but special et licite, avec une organisation materielle et 
administrative, commandée par le but à atteindre. "On peut distinguer de la corporation ou groupement de personnes que rassembent leurs efforts pour la realisation d'un but commum, avec quelque discipline. Celles ci sont les "universitas personarum", celles-là sont les "universitas bonorum"

On admet, donc, dans la typologie des personnes morales, les corporations et les fondations.

L'article a le but de montrer que la distinction faite pour la Teorie Générale du Droit, entre fondations et corporations, permet une configuration parallèle de tous les deux dans le champ du Droit Civil et du Droit Administratif.

Le "constitutif réel" de la fondation est dans le champ de la Teorie Générale du Droit; la configuration specifique des personnes morales suivant les principes e modèles du Droit Privé et du Droit Public c'est toute une autre chose.

$\mathrm{Si}$ on admite la notion de fondation que on a exposé ci dessus, on peut arriver, avec quelques notes de plus, à la fondation de Droit Public. C'est une personne morale crée par loi, avec le but d'un service public determiné par l'État; elle a son patrimoine, detaché du patrimoine public general et afectté a un but public; elle se trouve sous le contrôle de l'Etat. Ce sont les caracteres de sa difference specifique.

Unitermos: Categorias; Categorias jurídicas; Pessoa; Pessoa jurídica; Fundação "in genere"; Fundação privada; Fundação pública.

\section{Introdução. A questão da existência e dos caracteres da Fundação de Direito Público}

A questão relativa à fundação de Direito Público tem dado margem a interessante debate doutrinário. Manifestam-se, a propósito, acentuadas divergências. Estas dizem respeito a dois pontos fundamentais: ao problema relativo à existência da referida entidade e ao concernente à sua natureza jurídica.

Quanto ao primeiro tema a ser examinado - aquele que se refere à existência da fundação de Direito Público - há diversidade de orientação. Enquanto alguns juristas negam a possibilidade de se configurar, juridicamente, a fundação na esfera publicista, outros afirmam que o Estado pode dar vida a tais entidades.

Os primeiros dizem que a fundação, por sua natureza e estrutura, é pessoa jurídica de Direito Privado, regida por normas da parte geral do Código Civil mesmo na hipótese de ser destinada à realização de obras de interesse público. Assim se expressa o Prof. Hely Lopes Meirelles: "As fundações não perdem a sua personalidade privada, nem se estatizam a ponto de serem consideradas órgãos autônomos estatais, ou entidades públicas, como se vem afirmando. São e continuam sendo pessoas jurídicas de direito privado, sujeitas às normas civis das fundaçōes (Cód. Civil, arts. 16, I e 24 a 30), mas destinadas a realizar atividades de interesse público, sob o amparo e controle permanentes do Estado. Esse controle se opera na linha institucional e governamental precisamente por- 
que a fundação posta a serviço do Estado não perde a sua característica de instituição privada, mas se coloca como ente auxiliar do Poder Público, e dele recebe recursos para a consecução de seus fins estatutários ${ }^{(1)}$. Assim ocorrendo, a fundação é sempre de Direito Privado, por ser estruturada nos moldes dessa disciplina jurídica.

Outros juristas, porém, repelindo esse ponto de vista, afirmam ser possível a fundação de Direito Público. Nada impede a configuração de uma autarquia fundacional. Pode o Estado, por lei, instituir uma entidade cuja estrutura venha a configurar a afetação, por uma pessoa pública, de um' patrimônio, a um fím específico (fim público ou satisfação de interesses gerais). É a lição de O.A. Bandeira de Mello, in verbis: "Desde que a pessoa jurídica tem capacidade específica de direito público e essa personalidade decorre de patrimônio disposto sob dada organização, para desempenho de atividade estatal, segundo a especialidade atribuída, em conseqüência de criação do Estado, surge como fundação pública, ou melhor, como autarquia fundacional"(2). Não há óbice algum à configuração de entidades fundacionais ao lado das entidades corporativas.

A primeira corrente está apegada à sistemática do Direito Civil; a segunda insiste em que a categoria fundação ultrapassa à órbita do Direito Civil, podendo servir de estrutura tanto às pessoas jurídicas de direito privado quanto às de direito público. Por outras palavras: a distinção fundamental das pessoas jurídicas em "universitas personarum" e "universitas bonorum" é válida em ambas as esferas do Direito, isto é, no Direito Privado e no Direito Público. Trata-se de distinção que transcende a esfera dessas disciplinas.

Corolário desse princípio é o entendimento de que tanto no primeiro quanto no segundo desses ramos do Direito pode ocorrer a diferenciação entre corporações e fundações. Diz Ruy Cirne Lima que a fundação é comum ao Direito Privado e ao Direito Público(3).

A fundação, antes de ser instituto do Direito Civil, apresenta-se como categoria a ser elaborada pela Teoria Geral de Direito. A tipologia das pessoas jurídicas é matéria que se inclui entre os conceitos jurídicos fundamentais. Portanto, os tipos estruturais - corporações e fundações - constituem categorias a serem estudadas pela Teoria Geral do Direito. Em conseqüência podem ter acolhimento nas duas esferas do Direito: na do Direito Civil e na do Direito Administrativo. Porque o Direito se biparte em Público e Privado, a categoria tem adaptação nos dois campos do mundo jurídico.

Este é o debate relativamente à questão inicial.

O segundo problema é o que diz respeito à natureza jurídica e regime dessas entidades. Costumam os autores indicar os elementos componentes das fundaçōes, completando o estudo com a análise da integração das mesmas no sistema jurídico, isto é, seu regime jurídico. 
No presente trabalho, procuraremos abordar os dois temas. Admitindo-se, como possível a fundação de Direito Público, é relevante indicar qual é o seu "modo de ser". Assim, pensamos chegar a uma síntese capaz de retraçar as características da fundação de Direito Público.

\section{A existência da fundação de Direito Público. $O$ debate doutrinário}

Alguns autores negam a existência da fundação de Direito Público. Dizem que a fundação é instituto particular do Direito Civil. Figura na enumeração das pessoas jurídicas de Direito Privado. A pessoa jurídica pode se configurar como associação, isto é, um agrupamento de pessoas com o propósito de alcançar fins comuns, ou uma fundação, isto é, uma entidade constituída por um patrimônio personalizado e afetado a um objetivo programado pelo instituidor. Segundo Clovis Bevilacqua, as fundações consistem em "complexo de bens (universistas bonorum) dedicadas à consecução de certos fins e, para esse efeito, dotados de personalidade"(4) Pois bem, os elementos constitutivos da fundação (patrimônio, fim específico indicado pelo instituidor, com indicação do modo de administração e aprovação do estatuto pelo Estado) revelam que se trata, na espécie, de negócio jurídico unilateral, típico do Direito Civil. A personalidade atribuída pela lei seria de Direito Privado. Não se pode confundi-la com a autarquia, que é pessoa jurídica de Direito Público, com capacidade administrativa para a consecução de serviços públicos específicos recebidos do Estado através de especial delegação. É o que se deduz da norma de definição contida no artigo 5-, I, do Decreto Lei no 900, de 29 de setembro de 1969. O estudo comparativo das normas do Direito Civil com as do Direito Administrativo indicariam diversidade de institutos, sendo impossível a uma entidade ser, a um só tempo, fundação e autarquia. Hely Lopes Meirelles assim se expressa: "Não obstante a expressividade da lei e a clareza da doutrina, alguns ilustres autores pátrios vêm sustentando a existência de "fundações públicas", ou "autarquias fundacionais", ou "autarquias potenciais", ou "autarquias de tipo privado". Ora, a expressão "fundação pública" traz uma contradictio in terminis, porque se é fundação está insita a sua personalidade privada, se é autarquia, é de personalidade pública'?').

Inexistiria, assim, a fundação de Direito Público, podendo-se configurar, no entanto, fundações de caráter privado instituídas pelo Poder Público. Estas não se identificam com as autarquias, sendo submetidas às normas do Direito Civil. Tanto isto é certo que cabe ao Ministério Público o controle de tais entidades.

As fundaçōes sempre pertenceram à esfera do Direito Civil. Esse é o entendimento dos que negam a possibilidade de se configurar a fundação segundo modelos do Direito Público. Esta era, em geral, a orientação doutrinária.

Semelhante entendimento decorre do fato de a fundação constituir, tradicionalmente, instituto delineado pelos cultores do Direito Privado, os quais re- 
traçavam-lhe as notas características em modelos privatísticos. Parece que a fundação deve ser sempre configurada nos moldes do Direito Civil. Esta tem sido a tendência, como assinala o Prof. Miguel Reale ${ }^{(6)}$.

Realmente, Clovis Bevilacqua, estudando o problema sob o aspecto do Direito Comparado esclarece: "as agremiaçōes de caráter privado e as fundaçöes emergem espontaneamente da vida social, como poderosos meios de resistência e de assalto na eterna conquista da natureza, em que se esgota e engrandece a humanidade. Mas, para que tenham vida legal, juridicamente producente se tem elas de modelar segundo os preceitos do direito privado..."( $)$.

Além disso, as "universitas rerum" do Direito Romano, entes semelhantes às fundaçōes e reconhecidos no período pós-clássico, eram disciplinadas por normas de caráter privado. Constituíam instituições de beneficiência (piae causae), decorrentes da afetação do patrimônio a fins religiosos ou filantrópicos. Tais entes foram motivados pelo Cristianismo, como esclarecem Alexandre Correia e Gaetano Sciascia ${ }^{(8)}$.

A concepção de fundação tem sua origem no instituto romano. Juan Iglesias ensina: "A legislação de Justiniano não chega a afirmar de modo decidido a personalidade dos patrimônios fundacionais. Contudo, não se pode negar que nela se encontram alguns traços de autonomia, quando diz que tem faculdades para herdar, reclamar créditos, propor ações, contrair permutas e locações enfitêuticas. São os pilares em que se assenta a concepção moderna de fundação "independente", isto é, da verdadeira fundação, no sentido jurídico"(9).

Muito embora seja este o aspecto histórico do fenômeno nem por isso se pode deixar de reconhecer, modernamente, a existência da fundação de Direito Público, como nova conquista do mundo jurídico, apta a atender a novas necessidades sociais.

O instituto que tem suas origens no Direito Romano, foi construído pelo Direito Civil moderno. Mas a análise das notas características evidencia que a fundação é uma categoria jurídica, mais ampla do que a instituição congênere do Direito Civil. Pode ser objeto de disciplina paralela no campo do Direito Administrativo.

Senão, vejamos.

O Código Civil Brasileiro, tendo apresentado uma classificação das pessoas jurídicas teria induzido alguns doutrinadores à conclusão de que a fundação representa instituto peculiar do Direito Civil, inexistindo disciplina paralela para a fundação no campo do Direito Administrativo. O Código Civil Brasileiro apenas enumera as diferentes classes de pessoas jurídicas para o fim específico de estabelecer a disciplina das pessoas jurídicas de Direito Privado. A norma 
que enumera diferentes espécies incluindo as pessoas jurídicas de Direito Público é simples norma de definição e, pois, de caráter secundário. As que dispõem sobre as pessoas de Direito Privado são as normas primárias, de sentido pleno. A enumeração não é exaustiva, tendo, apenas, por objetivo delimitar as fundações que devem ser consideradas de Direito Privado, sem excluir a possibilidade de entes semelhantes na esfera do Direito Público. O Código Civil se restringe à fundação de Direito Privado. Dessa disciplina normativa não se pode concluir pela impossibilidade de ser o instituto também modelado por disciplina normativa de outra ordem.

Assim é certo que o instituto não é peculiar ao Direito Civil. Por outro lado, também é evidente que não é imprescindível que toda e qualquer fundação deva se configurar segundo modelos civilistas.

Este é o argumento de ordem legislativa.

Sob o ponto de vista doutrinário, nada há que justifique o primado do Direito Civil na conceituação e classificação das fundações. Ao Direito privado cabe, é certo, especificar a capacidade, o objetivo, o controle, enfim, a estrutura das fundações privadas. $\mathrm{O}$ mesmo ocorre com o Direito Público, relativamente as fundaçōes públicas. $\mathrm{O}$ problema da estrutura das pessoas jurídicas constitui matéria da Teoria Geral doL ireito. Não se pode confundir a questão do constitutivo real do ente fundacional (essência) com o de sua configuração concreta (existência no mundo jurídico). J leste último é que se apresentam as diferenças específicas encontradas nas diversas espécies (modos de ser). De início, é necessário definir o que seja uma fundação in genere como pessoa jurídica, para, depois, verificar a possibilidade de seu desdobramento em fundação privada fundação pública.

Ora, essa problemática não pode ser resolvida nem pelo Direito Civil, nem pelo Direito Administrativo. Estes, na disciplina das pessoas jurídicas privadas ou estatais já se defrontam com as noções de pessoa e de fundação previamentes delimitadas pela Teoria Geral do Direito.

Logo, é preciso ascender aos conceitos jurídicos fundamentais.

Como bem demonstra o Prof. José Cretella Júnior, a fundação in genere, isto é, como categoria, é um "patrimônio personalizado afetado a um fim", tendo, portanto, três notas típicas: universidades de bens, personalização e finalidade ${ }^{(10)}$

Ocorre que o sistema normativo se subdivide em, pelo menos, duas esferas: a do Direito Público e a do Direito Privado. A elaboração das fundações, pela Teoria Geral do Direito, encontra complementação, em ambas as disciplinas. Estas somente acrescentam ao ente fundacional algumas notas específicas 
quando procuram enquadrá-lo nos respectivos sistemas. Por isso, não se pode atribuir ao Direito Privado o primado e a exclusividade para modelar o instituto.

O Prof. José Cretella Júnior ensina: “A fundação considerada sob essa perspectiva, é um primeiro momento da ciência do Direito, do qual a fundação privada e a fundação pública constituem um segundo momento". E acrescenta: "Empregando pois o método científico adequado, que afasta pré-noções, que deixa de lado as posições petrificadas, é possível captar,a categoria jurídica fundação e dela atingir as duas espécies paralelas e inconfundíveis - a fundação privada e a fundação pública"(11).

Realmente não se pode confundir a questão estrutural, com a do regime fundacional. $\mathrm{O}$ estudo metódico do problema, separando as duas questões, permite distinguir entre as pessoas jurídicas, as corporações e as fundaçōes, e permite, ainda, classificá-las, segundo a capacidade jurídica, em corporações públicas e privadas, de um lado, e fundações, públicas e privadas, de outro.

Roberto de Ruggiero, após se referir a teoria tradicional que distingue as pessoas jurídicas em dois tipos fundamentais, a saber, as corporações e fundações, demonstra que, prescindindo-se dessas formas estruturais, de quem podem se revestir referidas pessoas, são estas entidades privadas ou públicas. Se é vontade do particular que determinou seu aparecimento, a entidade, corporação ou fundação é de Direito Privado. Se é a vontade do Estado que determinou seu nascimento, a entidade, corporação ou fundação é de Direito Público (' 2 ).

Da mesma forma Alessandro Groppali, ao efetuar a classificação das pessoas jurídicas, distingue-as em corporações e fundações, segundo o critério da estrutura ou em pessoas públicas ou privadas, segundo o critério da capacidade jurídica, escopo e controle a que as mesmas se submetem. Logo, é possível que uma pessoa jurídica seja, estruturalmente, uma fundação e, sob o ponto de vista do seu regime, uma fundação pública ${ }^{(13)}$.

Tais distinções são fundamentais para a apreciação da matéria. Permitem, de um lado, demonstrar a possibilidade jurídica da fundação de Direito Público, como modalidade de órgão autárquico e, por outro, estabelecer as necessárias delimitações entre referida pessoa e a fundação privada instituída pelo Poder Público.

3. A fundaçāo na Teoria Geral do Direito. O problema de personalidade moral.

Cabe à Antropologia Filosófica o estudo relativo à essência, auto-realização e autodesenvolvimento do homem. Para tanto, intenta conhecer a natureza e os princípios constitutivos do ser humano, indicando em que consiste sua realização segundo a ordem traçada por sua natureza. 
Segundo Roger Verneaux, pessoa é o "homem espiritual que transcende do universo por sua liberdade, aberto a todo ser e capaz de entrar em comunhão com as demais pessoas"(14). O homem transcende ao nível biológico e a toda sociedade temporal, segundo idêntico pensamento de Jacques Maritain ${ }^{(15)}$. Por isso, um dos conteúdos morais da idéia de Direito é o do valor da pessoa humana ${ }^{(16)}$ Não destoam semelhantes colocações do pensamento do primeiro escolástico, que foi Boécio: "Persona est rationalis naturae individua substantia".

Em virtude das qualidades que perfazem o estatuto ontológico da pessoa, o ser humano, portador de razão e entendimento (capacidade de conhecimento) e de vontade livre (capacidade de agir com conhecimento de causa mediante livre eleição e decisão) é considerado sujeito natural da ordem normativa.

O homem, em virtude de sua própria natureza é pessoa e, pois, sujeito de direito. Icilio Vanni, apesar de positivista, assim se expressa: " $\mathrm{O}_{\|}$lomem antes de ser pessoa no sentido jurídico, é pessoa no sentido antropológico. Em sua própria constituição psicofísica leva o homem os elementos e as condições para que o Direito possa reconhecer-lhe a capacidade de sujeito de Direito"(17).

Assim sendo, o conceito técnico jurídico de pessoa (em contraposição ao de objeto do direito) como protagonista da ordem social e jurídica tem correspondência com o de pessoa, definido pela Antropologia Filosófica. A capacidade de ser sujeito de direito deriva da própria natureza humana.

Mas a mesma faculdade tem sido reconhecida às pessoas jurídicas, ou mais explicitamente, a todo agrupamento de seres humanos que, com disciplina e ordem, congregam esforços para a realização de fins" comuns. A causa material é integrada pelos seres humanos; a causa formal pela união necessária em torno de objetivos comuns.

A questão é, então, a seguinte: possuem estes entes personalidade tão completa quanto a das pessoas naturais?

Hans Kelsen e Francisco Ferrara criticam a teoria tradicional, que identificou o conceito de sujeito de direito com o de pessoa, no sentido da Antropologia Filosófica.

Anotam ambos que a personalidade jurídica, tanto referente aos seres humanos quanto aos entes coletivos é, apenas, uma categoria jurídica, forma de unificação, para certos fins, de relações humanas. Personalidade jurídica, para Hans Kelsen, é tão-somente, um meio de que se vale a Ciência do Direito para imputação das condutas dos seres humanos que atuam em nome da sociedade. Diz Kelsen: "a pessoa jurídica no sentido estrito da palavra não é senão a personificação de uma ordem que regula a conduta de vários indivíduos, a saber, um ponto comum de imputação de todos aqueles atos humanos determinados 
pela mesma ordem". A atribuição de personalidade na pessoa jurídica é uma situação idêntica à da pessoa física. Kelsen esclarece: "A chamada pessoa física é a personificação de um complexo de normas que regulam a conduta de um mesmo indivíduo"(18). Em ambas as hipóteses ocorre uma construção jurídica, um artifício técnico, decorrente da teoria da imputação normativa. Também Ferrara entende que a personalidade é uma categoria jurídica, uma forma jurídica de unificação de relaçōes. $O$ Direito Objetivo reconhece personalidade ao agrupamento dos seres humanos que se associam para a consecução de objetivos comuns. As sociedades passam a ter, então, personalidade diversa da dos elementos que a compõem ${ }^{(19)}$.

Tais coletividades se compōem de indivíduos que tencionam alcançar fins comuns. Ao conceder-lhes personalidade, o Direito unifica sua atuação e favorece seu desenvolvimento e expansão.

Não é diferente o que ocorre com as fundações. Considera-as o Direito como pessoas jurídicas para unificar as atividades concernentes aos serviços para os quais foram instituídas pelo fundador.

A questão é mais complexa. $O$ Direito não é pura técnica. O substrato da pessoa não pode ser indiferente ao jurista. Segundo observa Del Vecchio, "a qualidade de sujeito de direito não depende, no homem, de uma concessão extrínseca e arbitrária de outra pessoa, já que deriva imediatamente da mesma natureza humana, até ao ponto em que o próprio indivíduo não dispõe do poder de aliená-la ou renunciá-la. Nesse sentido, a lei que atribui a cada um a condição jurídica de pessoa, ainda que nāo esteja sancionada pela ordem positiva, é uma lei natural"(20). Pessoa em sentido filosófico e pessoa em sentido jurídico são conceitos diferentes, mas se referem à mesma realidade. Javier Hervada ensina: "Todo sistema jurídico positivo se baseia, pelo menos, na juricidade natural dos homens, isto é, em que por natureza existe a capacidade e a tendência de relacionar-se juridicamente... A juricidade natural significa que, por nature$\mathrm{za}$, o homem está relacionado juridicamente com os outros sendo, em conseqüência, protagonista do sistema jurídico. Ser pessoa não é de origem positiva, senão natural, porque os homens, por natureza, são sujeitos de direito"(21).

A função da técnica, na espécie, não é outra coisa senão a de colocar a pessoa sob o signo do Direito, acrescentando-lhe a nota de protagonista do cenário jurídico.

Quanto aos agrupamentos humanos que são constituídos para alcançar fins comuns mediante colaboração dos seus integrantes, pode-se dizer que estes, por analogia, participam do conceito de pessoa. Na sociedade, como assinala Donald Pierson, existem as notas características do "consenso, solidariedade, ação conjugada, posição e função no grupo, tratamento dos indivíduos mediante entendimentos e sentimentos comuns com o propósito de desenvolver personalidades e agir conjugadamente na realização de fins comuns",(22). 
As corporações e as fundações existem para possibilitar ao ser humano o pleno desenvolvimento de suas potencialidades. Assim sendo, tem suas raízes nos "fins existenciais humanos". A propósito, Johannes Messner ensina: "a estrutura natural da sociedade, em sua totalidade, encerra um pluralismo social, e, em conseqüência, as comunidades e as sociedades menores, que têm suas raízes nos fins humanos existenciais, estão dotadas de traços de dignidade e de liberdade próprias da pessoa humana"(23).

Tais traços característicos permitem que as sociedades sejam consideradas pessoas, por analogia. Não discrepa desse entendimento a natureza das fundações. Estas constituem entidades que têm raízes, em última instância, na vida social. Os mesmos fundamentos que justificam a atribuição de personalidade jurídica às sociedades devem prevalecer para as fundaçōes. Diz, expressamente, Karl Larenz: "Se o ordenamento jurídico atribui à fundação capacidade jurídica, tratando-a como sujeito de direito, de modo idêntico à pessoa física, isto se baseia numa analogia justificada pelo fato de que a vontade do fundador, objetivada ao instituir a fundação, é atualizada de novo e outra vez pela atividade dos órgãos que cumprem referida vontade; portanto, também neste caso, de modo idêntico ao da associação, pode-se encontrar uma unidade de atuação no sentido de uma realidade objetivo-imaterial e sociológica"(24).

Justifica-se, portanto, a consideração analógica, para o fim de atribuição de personalidade jurídica, nos termos do pensamento de Messner, corroborado por Larenz.

Não se trata, portanto, de mera imputação normativa, decorrentes de simples processo de pura técnica. $O$ processo técnico reveste-se de importância, mas não pode ser desconectado de dados prévios, da "natureza das coisas". Por outras palavras: pensamos que o aspecto lógico formal do conceito jurídico de pessoa deve ser admitido como correto, já que é exata a afirmação segundo a qual o Direito, como técnica, exibe um processo de imputação normativa. Mas essa imputação não pode ser arbitrária decorrência do processo de construção. Este processo está delimitado pela valoração que preside a toda e qualquer construção da técnica jurídica. E a valoração decorre do estatuto ontológico da pessoa.

\section{A fundação no Direito Privado. Notas Características.}

A origem, a estrutura e os contornos da fundação têm sido estudados pelo Direito Civil, de longa data. Mas seus cultores, naturalmente, apreciam-na segundo características próprias dessa disciplina jurídica.

Em síntese, vejamos a conceituação civilística para posterior confronto com a apresentada pelo I lireito Administrativo.

V. Rossel e H. Mentha, juristas suíços, com base no artigo 60 do Código 
Civil Suíço, definem a fundação como "a afetação de um patrimônio a um objetivo especial e lícito, em geral permanente, com uma organização material e administrativa comandada pelo objetivo a realizar"(25) Do mesmo entender é a colocação de Andrea Torrente: "o negócio de fundação é o ato com o qual uma pessoa separa alguns bens do próprio patrimônio e lhe destina a um escopo determinado"(26).

A fundação é, na verdade, um ente social com personalidade jurídica, compreendendo os órgãos encarregados de sua administração, os quais dispõem de patrimônio próprio para o fim de realizar a afetação dada pela vontade do instituidor. Há todo um conjunto de relações de seus participantes: fundador, destinatários presentes e futuros que se beneficiam do patrimônio e órgãos de gestão. De uma forma ou de outra, todos são co-autores, coparticipam para a realização da obra fundacional. Esta alcança seus fins pela vontade do fundador, que indica o escopo e estabelece os destinatários; pelo patrimônio, posto por aquele à disposição da mesma meta; e pela administração ou gestão, também prevista pela vontade do fundador. A obra pode ir avante graças aos recursos materiais do patrimônio reservado pelo fundador, e à ação diligente dos encarregados do poder de dirigí-la.

Esta é a realidade fundacional. Seu organismo é complexo. Constituída para viver indefinidamente, desde que o fim seja realizável e se disponha de patrimônio para atender às suas necessidades, tal organismo difere do da sociedade.

Por isso, a distinção entre corporações (universitas personarum) e fundações (universitas bonorum) que o Direito Civil incorporou à sua doutrina é de suma importância. Permite retraçar as notas características das fundações e entrever a possibilidade da fundação de Direito Público. Esta é plenamente compatível com a noção civilística.

As corporações constituem agrupamentos de pessoas que, com certa disciplina, unificam seus esforços para a obtenção de um fim comum. As fundações são "complexos de bens destinados por ato irrevogável de vontade a um certo fim, com caráter de perpetuidade ou de duração indeterminada" consoante excelente síntese de Del Vecchio ${ }^{(27)}$.

No caso das corporações prevalece o elemento pessoal, embora não possa faltar o elemento patrimonial; no caso das fundações, o elemento patrimonial é o prevalente, ainda que deva estar presente o elemento pessoal, já que é a vontade do fundador que se manifesta no ato de instituição, devendo ser realizada na vida da fundação.

O confronto entre referidos entes foi apresentado, de maneira nítida, por Alberto Trabucchi. Diz o jurista que as corporações se distinguem das funda- 
ções sob tríplice aspecto: o escopo, a vontade e os órgãos dirigentes. " $O$ escopo, nas associações, é interno e próprio da entidade, que é constituída para outorgar vantagens aos seus associados; nas fundações, ao contrário, o interesse que se procura é externo e a entidade só tem por função realizar vantagens para outros. No que se refere à vontade, esta nas fundaçōes é externa ao ente já que provém do fundador; nas associações, é interna, já que deriva dos mesmos membros da entidade que dispōem sobre sua constituição, governo e fim da pessoa jurídica. No que se refere aos órgãos diretivos, nas associações os mesmos são dominantes; nas fundações, submetem-se à vontade de quem constituiu o ente",(28).

O fim, a organização e a previsão de recursos constituem os elementos da fundação. Contudo, o elemento vontade, referido por Trabucchi, merece especial consideração. Nas fundaçōes, proclama o jurista, a vontade é externa, enquanto que nas associações é interna. Realmente, a configuração da entidade em estudo depende, antes de mais nada, do negócio fundacional, que é um ato de destinação, uma declaração de vontade, cujo conteúdo deve ser a fixação do objetivo e a destinação do patrimônio. A fundação é, nesta ordem de considerações, uma organização que provém da referida declaração de vontade. Nesse sentido é a conceituação de Pierre Pescatore, in verbis: "a fundação é uma pessoa moral, encarregada conforme a vontade do fundador, da administração de um patrimônio afetado a uma obra determinada e à gestão dessa obra'(29).

O que caracteriza a fundação é, em última análise, o elemento vontade, que, no caso, prevem do fundador, sendo, como diz Trabucchi, exterior ao ente. Tem razão Limongi França ao afirmar que o fato da associação consciente é nota peculiar à natureza humana, não havendo, a rigor, sociedade de bens. A referência à sociedade de bens é admissível apenas para ressaltar a importância do patrimônio, completa o citado mestre ${ }^{(30)}$.

Forçoso é convir que a fundação depende da vontade do fundador, mas esta vontade se perpetua e é atualizada pela atividade humana dos órgãos que a executam, como preleciona Karl Larenz.

O patrimônio, juridicamente falando, é objeto, não podendo ser considerado sujeito de direito. Logo, não é ele que define a fundação na sua essência. É incorreto, salienta Heinrich Lehmann, qualificar a fundação pelo patrimônio de destino. A vontade na associação é autônoma, pois é decisiva para sua configuração; mas na fundação ela é heterônoma, vem determinada pelo fundador no negócio fundacional, limitando-se os administradores a seu exato cumprimento. Segundo o citado jurista, "o decisivo, em contraposição com a associação, é que a fundação não consiste em uma união de pessoas, cuja vontade determine o fim da fundação, senão que este vem imposto pela vontade do fundador no documento de fundação. Os administradores da fundação devem se limitar a cumprir esta vontade. A vontade da fundação é heterônoma, vem determinada pelo fundador no negócio da fundação"(31). 
Nesta ordem de idéias, pode-se adotar, para fins do pretendido confronto entre a fundação privada e a fundação pública, conceito analítico de fundação privada adotado por Heinrich Lehmann, a saber: "fundação é uma organização criada por declaração de vontade privada para a obtenção de um fim duradouro, dotada de personalidade jurídica independente, e que não consiste numa aliança de pessoas, senão que está dotada de meios patrimoniais para alcançar o fim estabelecido no negócio fundacional"(32).

As notas características da conceituação de fundação privada decorrente do Direito Civil acrescentam alguns elementos à definição de fundação in genere, como categoria, decorrente da Teoria Geral do Direito. As diferenças específicas são as que se referem à origem, ao fim e à função da entidade. Com efeito, a fundação privada tem sua origem na vontade do fundador; está adstrita, sob o ponto de vista teleológico, à realização dessas atividades sociais (singulorum utilitas) sem atingir as que dizem respeito à satisfação de interesses públicos, sendo, por isso, submetida aos princípios setoriais que informam os institutos do Direito Civil.

Tais notas específicas não destroem o princípio da unidade substancial inerente ao conceito emitido pela Teoria Geral do Direito.

Vejamos, porém, as notas que o Direito Administrativo atribui às fundações públicas. Estas se configuram em outros moldes, assumindo feições próprias e inconfundíveis. Assim, poderemos estabelecer a almejada linha de confronto entre ambos os institutos.

5. A fundação no Direito Público. Notas características. Confronto com a fundação de Direito Privado.

Definida a fundação in genere, como categoria jurídica, cabe verificar se o instituto pode ser disciplinado por ambas as disciplinas jurídicas, isto é, pelo Direito Civil e pelo Administrativo. Por ser o instituto tradicionalmente disciplinado pelo Direito Civil, alguns juristas tem entendido que se trata de matéria privativa dessa disciplina jurídica.

Seguindo a recomendação do Prof. José Cretella Júnior, segundo a qual é necessário um estudo preliminar da categoria fundação in genere, para, ao depois, verificar a análise das espécies, procuramos apresentar, nos parágrafos anteriores, algumas consideraçōes sobre a pessoa jurídica no âmbito da Teoria Geral do Direito.

A fundação é, antes de mais nada, uma categoria. Assiste razão ao ilustrado mestre.

Senão, vejamos. Como ensina Eduardo Garcia Maynez, o Direito estuda- 
do sob o ponto de vista formal, implica em determinados objetos lógicos, os quais decorrem deste conceito lógico jurídico fundamental: "direito é a regulação bilateral, externa e coercível do comportamento humano". São conceitos implicados nessa definição os de norma atributiva e norma prescritiva. A regulação jurídica consiste na "conexão necessária e recíproca de uma norma que obriga e outra que faculta". Esse caráter bilateral condiciona, por sua vez, a exterioridade e a coercibilidade. Como conceito implicado no de regulamentação bilateral corresponde, no plano de conduta, o de relação jurídica, que estabelece vínculos entre o sujeito do direito e o sujeito do dever. Assim, diz Garcia Maynez: "sujeito de direito é qualquer ente capaz de intervir, como pretensor ou como obrigado, numa relação jurídica". E acrescenta: "os sujeitos de direito são individuais ou coletivos. Substratum do primeiro é o homem. O substratum da pessoa jurídica pode ser bem uma coletividade de indivíduos (universitas personarum), bem de um patrimônio de afetação ou destino (universitas bonorum)". A tipologia das pessoas jurídicas é matéria que se inclui entre os conceitos jurídicos fundamentais. Fundação é, pois, um conceito lógico jurídico fundamental $^{(33)}$.

Da mesma forma, Rafael Preciado Hernandez, cuja obra revela notável contribuição neotomista, inclui a pessoa, natural ou jurídica, entre os conceitos jurídicos fundamentais de caráter material, e o sujeito, como mero destinatário da norma, entre os conceitos jurídicos fundamentais de caráter formal. Neste último caso, ele é considerado como titular da faculdade ou direito subjetivo e titular da obrigação ou dever jurídico. Entre os sujeitos, está incluída a fundação ${ }^{(34)}$. No mesmo sentido é o parecer de Luis Recasens Siches ${ }^{(35)}$.

Realmente, um é o problema da estrutura, outro o da capacidade jurídica: o primeiro é o objeto da Teoria Geral do Direito; o segundo, das disciplinas jurídicas, a saber do Direito Civil e do Direito Administrativo.

Assim é possível a existência de fundação pública desde que a configuração desta se conforme, de um lado, ao paradigma da fundação e, por outro, esteja de acordo com os cânones do Direito Administrativo.

Andrea Torrente diz expressamente que as pessoas jurídicas, em qualquer de suas modalidades, isto é, associações e fundações se distinguem em pessoas de direito público e de direito privado: as primeiras, destinadas a perseguir interesses gerais são disciplinadas pelo Direito Administrativo; e as segundas, destinadas a interesses de natureza singular, que não podem ser incluídas entre os fins do Estado, são regidas pelo Direito Civil ${ }^{(36)}$. Idêntica é a lição de Karl Larenz, segundo o qual "entre as pessoas jurídicas, tanto de direito privado quanto de direito público, devem-se distinguir as associaçōes, nas quais é essencial a existência de membros, das instituições e fundações, que dispõem unicamente de órgãos, isto é, administradores para a realização das missões a ela encomendadas"(37). 
Em suma: tanto na esfera do Direito Civil quanto na do Direito Administrativo são possíveis corporações e fundaçōes.

Já analisamos as pessoas jurídicas no âmbito do Direito Civil. Vejamos como se definem as pessoas jurídicas estatais.

Segundo o Prof. José Cretella Júnior, autarquia é "toda pessoa jurídica pública que, dentro dos limites do direito objetivo e com capacidade para administrar-se, é considerada pelo Estado como um de seus entes". Estas pessoas se desdobram em fundações e corporações. Fundação pública consiste "numa afetação, por uma pessoa pública, de um patrimônio a um serviço público personalizado, criado pela pessoa pública, com regime jurídico próprio, informado por princípios de direito público". Corporação pública consiste numa "pluridade de pessoas físicas determinadas que se agrupam, personalizando-se para a consecução de fins de interesse público"(38).

As autarquias são, portanto, corporações públicas ou fundações públicas. De acordo com as definiçōes acima transcritas, forçoso é convir que elas se distinguem pela estrutura, isto é, pelo seu constitutivo real. As corporações são constituídas pelo agrupamento de pessoas que se reúnem para a consecução de um objetivo comum (no caso, de interesse público); as fundações constituem decorrência da afetação de um patrimônio a um fim público. Nada impede a adoção, pelo Direito Público, da distinção entre corporação e fundação, para a caracterização das pessoas públicas que constituem objeto de sua regulamentação.

Logo, a distinção entre as entidades que se encontra na Teoria Geral do Direito, revive no Direito Civil e persiste no Direito Administrativo. Contudo, as fundações públicas se distinguem das privadas por certas notas específicas.

Não há, porém, que confundir as fundações de Direito Público com as fundações de Direito Privado instituídas pelo Estado. Pode o Estado instituir pessoas de Direito Privado para cumprir objetivos imprescindíveis ao aprimoramento da vida social. Apesar de estas fundações serem de iniciativa do Estado (criadas por lei), contanto, para sua efetiva realização, de recursos advindos do patrimônio público, não perdem a natureza de Direito Privado, ficando sujeitas à fiscalização por seus atos ao órgão do Ministério Público. As vicissitudes dessas fundações se subsumem nas normas do Código Civil, enquanto que as fundações de Direito Público, por serem parcelas de Administração, se enquadram no sistema normativo do Direito Administrativo. São autarquias. O regime jurídico é o critério que permite distinguir entre a fundação de Direito Público e a fundação de Direito Privado instituída pelo Estado.

O poder público pode criar corporações ou fundações. Estas podem ser públicas ou se revestir das características do Direito Privado. 
Nesta ordem de idéias, duas conclusões se impõem: em primeiro lugar, as fundações públicas constituem uma realidade jurídica; em segundo lugar, sua configuração obedece aos cânones do Direito Administrativo.

A fim de estabelecer um paralelo entre o conceito de fundação privada, transcrito da obra de V. Rossel e H. 1 entha, vejamos a noção de fundação pública, consoante o ensinamento de André Buttgenbach.

Diz o jurista belga que a fundação pública consiste na "afetação realizada, pelas autoridades públicas, de um patrimônio especial, juridicamente distinto do patrimônio geral do poder criador, a um serviço público que, para a gestão desse patrimônio e a realização de seu objeto, é dotado de autonomia orgânica técnica, sob a tutela e o controle deste último"(39).

Desta definição, pode-se, de início, deduzir que a fundação pública é uma autarquia. Trata-se de órgão dotado de autonomia orgânica e técnica, colocado sob a vigilância do Estado, como ressalta o citado jurista. Seus elementos são os seguintes: a) escopo, consistente na prestação de um serviço público, determinado pelo Estado (princípio da finalidade); b) administração entregue a um serviço público dotado de autonomia para a gestão do patrimônio; c) patrimônio, distinto do patrimônio geral, que é destinado com exclusividade ao fim previsto (princípio da especialidade e da indisponibilidade).

Além disso, outras notas decorrentes destas são importantes. Segundo ensina o Prof. José Cretella J únior, a criação, extinção e transformação desses órgãos depende, em todos os casos, de texto legal. Além disso, adianta o ilustre mestre que a fundação, de um lado, goza das prerrogativas de potestade pública, e, por outro, é atingida por restrições e sujeições, por estar vinculada, em ambas as hipóteses, aos interesses públicos, estando, em consegüência, sujeita à vinculação tutelar e processo especial de prestação de contas ${ }^{(\sharp 0)}$.

Por isso, as fundações são informadas pelos princípios setoriais da autoexecutoriedade, da autotutela e da especialidade, entre outros ${ }^{(41)}$.

Tais notas permitem extremar a fundação de Direito Público da de Direito Privado. O escopo, na fundação de Direito Privado, é determinado por ato de vontade (negócio fundacional) do fundador; na de Direito Público, é o Estado quem determina o fim-atuação da fundação, sempre subordinado à prestação de serviço público. A administração, na fundação de Direito Privado, pode ser determinada, de antemão, pelo fundador; na fundação de Direito Público, é o Estado quem determina a exigência do serviço público a ser cumprido, o qual pode sofrer as convenientes adaptações, sempre a cargo do Estado. $O$ patrimônio, na fundação de Direito Privado, provém do ato de dotação do instituidor; na de Direito Público, o patrimônio é do Estado, sendo especialmente destacado e afetado ao fim-público. $\mathrm{O}$ controle e a vigilância, na fundação de Direito 
Privado é de caráter negativo, limitando-se o Estado a impedir que a vontade do fundador seja desprezada e violada a ordem pública (vigilância exercida pelo fiscal da lei, o Ministério Público); na fundação de Direito Público é positiva, já que cabe ao Estado promover a atividade programada e exigir seu integral cumprimento (tutela administrativa e vigilância ininterrupta).

Com tais características, nota-se que a fundação de Direito Público, consistente na afetação jurídica especial, pelos órgãos públicos, de um patrimônio, a um serviço público, nos precisos termos da definição de André Buttgenbach, distingue-se, nitidamente, da fundação de Direito Privado, devidamente conceituada por Rossel e Mentha. Organicamente, é um serviço público descentralizado e autárquico, criado pelo Estado, com autonomia técnica, administrativa e financeira, tendo seu próprio regime jurídico.

\section{Conclusōes. Nossa posição.}

As conclusōes deste estudo podem ser fixadas nos seguintes enunciados:

I. Doutrinariamente, inexiste fundamento para se rejeitar a existência da fundação de Direito Público. O estudo da categoria fundação cabe à Teoria Geral do Direito. Trata-se, no caso, de conceito jurídico fundamental para toda e qualquer configuração jurídica posterior. Sendo conceito básico, a categoria compreende, ordena e serve de apoio a outros que lhes são subordinados.

II. A divisão estabelecida pela Teoria Geral do Direito, entre corporações (universitas personarum) e fundações (universitas bonorum) possibilita semelhante distinção nas esferas jurídicas do Direito Privado e do Direito Público havendo, em conseqüência, corporações e fundações privadas ao lado de corporações e fundações públicas.

III. A tipologia das pessoas jurídicas é, assim, matéria da Teoria G eral do Direito. Cabe-lhe delimitar, dentro dessa classificação, a fundação "in genere", a qual serve de paradigma para as disciplinas jurídicas. Não se pode confundir o "constitutivo real" com a "configuração concreta" Nesta se manifesta a diferença específica, já que os atributos acrescentados pelo Direito Administrativo ao gênero próximo passam a configurar a espécie.

IV. A fundação se manifesta, com características próprias, no Direito Civil e no Direito Administrativo, sendo juridicamente configurável a fundação de Direito Público. A bipartição não rompe a unidade do conceito; permite, apenas, a atribuição de regime adequado às peculiaridades de cada caso.

V Não deve a fundação de Direito Público ser estudada nos moldes privatísticos. As fundaçōes públicas constituem uma realidade jurídica, obedecendo sua configuração aos cânones do Direito Administrativo. 
VI. No Direito Público, suas feições próprias, elevam-na à categoria de ente autárquico, decorrendo esta conclusão do exame de sua natureza em confronto com as instituições opostas e similares.

VII. Seus caracteres são os seguintes: escopo, consistente em serviço público criado por lei e determinado pelo Estado; administração entregue a um serviço público dotado de autonomia para a gestão técnica e patrimonial da entidade; patrimônio próprio, distinto do geral, destacado e afetado a um fim-público; tutela administrativa e vigilância positiva do Estado.

\section{Referências Bibliográficas}

(1) Lopes Meirelles, Hely, Direito Administrativo Brasileiro, 8ª ed., R.T., 1982, p. 350.

(2) Bandeira de Mello, Oswaldo Aranha, Princípios Gerais do Direito Administrativo, vol. II, Forense, 1 974, p. 203.

(3) Cirne Lima, Ruy, Princípios de Direito Administrativo, 6를., R.T.,1 987, p. 66.

(4) Bevilacqua, Clovis, Teoria Geral do Direito Civil, $2^{\underline{a}}$ ed., Livraria Francisco Alves, 1929, p. 158/159.

(5) Lopes Meirelles, Hely, Direito Administrativo Brasileiro, $8^{\mathrm{a}}$ ed., R.T., 1982, p. $351 / 352$.

(6) Reale, Miguel, Direito Administrativo, Forense, 1969, p. 5, $17 / 27$.

(7) Bevilacqua, Clovis, Resumo das Liçōes de Legislação Comparada sobre o Direito Privado, Fonseca Magalhães, Bahia, 1987, p. 151/152.

(8) Correia, Alexandre e Sc iascia, Gaetano, Manual de Direito Romano, 4ㄹ ed., Saraiva, 1961, p. 52.

(9) Iglesias, Juan, Derecho Romano, Instituiciones de Derecho Privado, 6⿳亠丷厂 ed., Ariel, Barcelona, 1972, p. 166/168.

(10) Cretella Júnior, José, Fundações \& Direito Público, Forense, 1976, p. 13.

(11) Cretella Júnior, José, obra citada, p. 10 e 65.

(12) De Ruggiero, Roberto, Instituiçôes de D ireito Civil, vol. I, trad. Ary dos S antos, Saraiva, 1 934, p. 430 e 451.

(13) Groppali, Alessandro, Avviamento allo Studio del Diritto, Milano, Dott A. Giuffré Ed., 1951, p. 124.

(14) Verneaux, Roger, Filosofia del Hombre, trad. L. Medrano, Herder, 1977, p. $233 / 234$.

(15) Maritain, Jacques, L'Homme et l'État, trad. da versão inglesa por Robert e France Prélot, Presses Univ. France,1 965, p. 12. 
(16) Coing, Helmut, Fundamentos de Filosofia del Derecho, trad. Juan Manuel Mauri, Ed. Ariel, Barcelona, 1976, p. 14

(17) Vanni, Icilio, Filosofia del Derecho, trad. Rafael Urbano, Libreria Beltran, Madri, 1941, p. 124.

(18) Kelsen, Hans, Teoria General del Derecho y del Estado, trad. EduardoG arcia Maynez, textos Universitarios, México, 1969, p. 113.

(19) Garcia Maynez, Eduardo, Introducción al Estudio del Derecho, 16ª ed., Ed. Porrua, México, 1969, p. 290 e segs.

(20) Del Vecchio, Giorgio, Les Principios Generales del Derecho, trad. Juan Ossorio Morales, 2ª ed., Barcelona, 1948, p. 77.

(21) Hervada, Jaxi er, Introducción Critica al Derecho Natural, Ed. Universidad de Navarra, Pamplona, 1981, p. 119.

(22) Pierson, Donald, Teoria e Pesquisa em Sociologia, 18 ${ }^{\mathrm{a}}$ ed., Melhoramentos, 1981; p. $155 / 156$.

(23) Messner, Johannes, Ética Social, Politica y Economia a la luz del Derecho Natural, trad. J.L. Barrios Sevilha, J.M. Rodriguez Paniagua e J. Enrique Diez, Rialp, Madrid, 1977, p. 197.

(24) Larenz, Karl, Derecho Civil, Parte General, trad. Miguel Izquierdo e Macias Picavea, Ed. Revista del Derecho Privado, Madri, 1978, p. 239.

(25) Rossel, V. e Mentha, H., Manuel du Droit Civil Suisse, vol. I, no 258, p. 171.

(26) Torrente, Andrea, Manuale di Diritto Privado, 6ª ed., Milão, Dott A. Giuffré, 1965, p. 74.

(27) Del Vecchio, Giorgio, Lezioni di Filosofia del Diritto, 9ª ed., Milão, Dott A. Giuffré, 1953, p. 277.

(28) Trabucchi, Alberto, Istituzioni di Diritto Civile, 26 ed., Padua, Cedam Casa Ed. Dott Antonio Milani, 1983, p. 107/108.

(29) Pescatore, Pierre, Introduction a la Science du Droit, Presses Universitaires, Luxembourg, 1960, p. 250/251.

(30) Limongi França, Rubens, Instituições de Direito Civil, Saraiva, S. Paulo, 1988, p. $71 / 72$.

(31) Lehmann, Heinrich, Tratado del Derecho Civil, Parte General, trad. José M. Navas, Ed. Rev. del Derecho Privado, 1956, p. 634.

(32) Lehmann, Heinrich, ob. citada, p. 658.

(33) Garcia Maynez, Eduardo, Logica del Concepto Juridico, Fundo de Cultura Economica, México, 1959, p. 157/159; 163; 178/183 e 188/189. 
(34) Preciado Hernandez, Rafael, Lecciones de Filosofia del Derecho, 6a- ed., Ed. Jus, México, 1970, p. 127/140.

(35) Recasens Siches, Luis, Introducción al Estudio del Derecho, 2-ed., Ed. Porrua, México, 1972, p. 148 e segs.

(36) Torrente, Andrea, ob. citada, p. 72.

(37) Larenz, Karl, ob. citada, p. 167.

(38) Cretella Júnior, José, Curso de Direito Administrativo, 5ª ed., Forense, 1977, p. 157; $265 / 267$.

(39) Buttgenbach, André, Theorie Générale des Modes de Gestion des Services Publiques en Belgique, Bruxelas, Maison Ferdinand Lacier, 1954, p. 305.

(40) Cretella Júnior, José, Fundações de Direito Público, Forense, 1978, p. 68/92.

(41) Cretella Júnior, José, Os Cânones do Direito Administrativo, separata da Revista de Informaçōes Legislativa do Senado Federal, nº 97, jan./março 1988.

São Paulo, janeiro de 1988. 